There are few reports of acute cerebellar ataxia presenting in adults and it is of interest that Brumlik and Means ${ }^{3}$ describe two American cases showing "lightening eye movements, peculiar shuddering tremor and cerebellar ataxia."

It is tempting to postulate that encephalitis tremens, a benign epidemic form of acute cerebellar ataxia with R.I.M.E.L. limited geographically to a region of West Africa rain forest, might represent an abor virus encephalitis involving the brainstem. However, such an assumption awaits investigation. -I am, etc.,

Royal West Sussex Hospital,

Hugh COAKHam

1 Wright, J., and Morley, D. C., Lancet, 1958, 1 2 Personal study while in receipt of Leverhulme 3 Brumlik, J., and Means, E. D., Brain, 1969, 92, 157.

\section{Oxytocin Release by Infused Prostaglandin}

SIR,-Dr. Arnold Gillespie and others, results on oxytocin release by infused prostaglandins (26 February, p. 543) are very interesting, but I feel that though the possibility cannot be excluded not enough evidence was provided to allow the conclusion that administered prostaglandins act directly on the pituitary to release oxytocin.

No peripheral oxytocin was detected in one patient in whom prostaglandins did not stimulate uterine activity. This could imply not only that direct prostaglandin-induced oxytocin release from the pituitary is required to enhance uterine activity when administering exogenous prostaglandins, but that prostaglandin-induced uterine contractions might indirectly stimulate the pituitary, even though this may be by release of further amounts of prostaglandin.

Amounts of oxytocin found in prostaglandin-induced labours were similar to those found in the late first stage of spontaneous labour, and seem to indicate little difference in pituitary involvement in these two situations. The observed oxytocin release in males and females could also arise indirectly from one of the many known pharmacological actions of prostaglandinsfor example, on renal and intestinal systems

As further evidence for posterior-pituitary involvement in the action of prostaglandins they cite investigations ${ }^{12}$ showing that spontaneous and prostaglandin-induced contractions can be inhibited by ethanol whereas exogenous oxytocin-induced contraction are not. This assumes that spontaneous contractions are the direct result of endogenous oxytocin release, which may not be so. Indeed one might hypothesize from this evidence that it is endogenous prostaglandin release that is effecting uterine contraction in spontaneous labour. Mantell and Liggins ${ }^{3}$ have shown that ethanol can reduce exogenous oxytocin-induced contractions, and therefore the use of ethanol to define the role of prostaglandins and oxytocin in the control of uterine activity must be viewed with some caution.-I am, etc.,

KeIth Hillier Nuffield Department of Obstetrics and Gynaecology, Radcliffe Infirmary,

Oxford

1 Fuchs, F., Fuchs, A-R., Poblete, V. F., and Risk, cology, 1967, 99, 627 .
2 Karim, S. M. M., and Sharma, S. D., Fournal of Obstetrics and Gynaecology

Mantell, C. D., and Liggins, G. C., fournal of Obstetrics and Gynaecology of the British Com monwealth, 1970, 77, 976.
moltrics

\section{Genetic Counselling}

SIR,-The table quoted by Professor C. A. Clarke (4 March, p. 606) from Redding and Hirschhorn gives a threefold increased risk of a subsequent sib being affected by Down's syndrome throughout the maternal age range. This is in fact the order of the overall increased risk to a mother who has had one affected child irrespective of her age or the type of chromosome anomaly. ${ }^{1}$ But Carter and Evans ${ }^{2}$ showed that most of the increased risk is due to balanced translocation or other factors than maternal age, A mother of a child with trisomy 21 , proper, where both parents have a normal chromosome complement, has only a very slightly increased risk above the appropriate to her age. Thus a mother aged 35 years or more at the birth of her first affected child has approximately the same risk of having a second child with Down's syndrome as other members of her age group.-I am, etc.,

BRIAN H. KIRMAN

Oueen Mary's Hospital for Children,

Carshalton 1 Berg, J. M., and Kirkman, B. H., Archives of
Disease in Childhood, 1961 , 36. 64 .
Carter. C. O., and Evans, K. A., Lancet, 1961,
2, 785 .

\section{Irritable or Irritated Bowel}

SIR,-Your leader on the "Irritable Bowel Syndrome" (22 January, p. 197) is an excellent summary of the confusion that has grown up around this symptom complex, which is so ill-defined that one wonders if it really exists.

Everyone is agreed that the function of the intestine is disturbed, and that as yet no structural abnormality has been demonstrated to account for the very genuine symptoms attributed to an irritable bowel. As there is no evidence that the bowel is intrinsically abnormal, it is a pity that the title of this leader perpetuates the assumption that the intestine is primarily at fault. Perhaps the cause of these symptoms should be soupht elsewhere.

There is a growing body of evidence which shows that our modern Western diet is abnormal and that this causes several diseases which have appeared on the clinical scene in this century. ${ }^{1-3}$ One of these diseases is diverticulosis of the colon, which has been said by some to be connected with the "irritable bowel syndrome." Certainly, both conditions are common in Western nations and almost unknown in rural Africans. ${ }^{4}$ It is also true that symptoms ranging from vague dyspepsia, heartburn, anorexia, nausea, distention, fullness, and flatulence to generalized abdominal aching and severe colic are common both to diverticulosis and to the irritable bowel syndrome. Furthermore, borh may be associated with bowel habits which may vary from constipation to episodes of diarrhoea or to the frequent passing of small hard stools.

In the case of diverticulosis, these symptoms are not caused by the diverticula be cause they can be relieved or abolished in
$85 \%$ of patients merely by replacing the cereal fibre that is lacking in our modern diet. This is done by adding unprocessed bran to the food and reducing the intake of refined sugar. ${ }^{56}$ Over the last five years, it has been my experience that a high fibre/ low sugar diet relieves or abolishes these very same symptoms in patients who do not have diverticula and in whom no abnormality of the intestine has been demonstrated. Consequently, I believe that these symptoms are often caused by an intestine that is struggling with our modern fibre-deficient diet.

None of the observations recorded in your leading article is inconsistent with the theory that these symptoms are caused by a normal bowel whose function is disturbed by its having to cope with an altered environment. This environment changed dramatically when the refining of carbohydrates became widespread only a century ago. The addition of fibre in the form of unprocessed bran in a quantity sufficient to render the stools soft and passed without straining will relieve these symptoms in most patients. The rural African passes soft bulky stools and does not suffer from diverticulosis or from an irritable bowel. In countries where the "irritable bowel syndrome" is common, the diet is so fibre-deficient that it causes the colon to rupture itself so that diverticula appear. If the bowel is being subjected to such an abnormal diet, is it fair to refer to the "irritable" bowel syndrome? Surely it would be wiser to refer to the "irritated" bowel syndrome.

The term irritable bowel syndrome implies that the design or construction of the intestine is intrinsically wrong and it cannot cope with the normal stresses of everyday life. Can this really be so in over half the patients who attend our clinics? It seems more likely that, owing to evolution and natural selection, their bowels are normal but their symptoms are caused by the food they eat. I am, etc., Manor House Hospital
London N.W.11

N. S. PAinter

Cleave, T. L., Campbell, G. D., and Painter N. S., Diabeles, Coronary Thrombosis and the
Saccharine Disease, 2nd edn. Bristol, J. Wright, Sacciar

2 Painter, N. S., and Burkitt, D. P., Briti-h Medical Painter, N. S., and Bur
foruna 3 Burkitt. D. P.. Lancer, 1970, 2. 1237.

Painter, N. S., British Medical fournal, 1971, 2. 156. Painter, N. S., Almeida, A. Z., and Colebourne,
K. W., British Medical fournal, 1972, in press.

\section{Vasodilating Action of L-dopa}

SIR,-The studies of Spiers and Calne ${ }^{1}$ and Spiers ${ }^{2}$ show that dona and dopamine have a noradrenaline-liberating action at the sympathetic nerve endings with depletion of stores. Both substances are also metabolic precursors of adrenaline and noradrenaline. In order to investigate a possible peripheral vasodilating action of $L$-dopa we have treated a group of 10 patients affected by an atherosclerotic obstructive arterial disease of the lower limbs for more than two years.

L-dopa was administered in increasing dosage from $375 \mathrm{mg} /$ day to a maximum of $3,000 \mathrm{mg} /$ day. All patients were treated for a month and no other drug was administered. Rheographic registrations ${ }^{3}$ were performed before, during, and after treatment. At the end of a month, three patients did not show any benefit. Seven patients showed subjective 